This paper reports a study into the peculiarities of the structural-phase composition of the alloy obtained by using anthropogenic waste from the production of high-alloy steels involving reduction melting. That is necessary for determining the technological parameters that could help decrease the loss of alloying elements in the process of obtaining and using a doped alloy. This study has shozen that at an $0: C$ ratio in the charge of 1.84 , the alloy consisted mainly of the solid solution of carbon and alloying elements in $\alpha-F e$. The manifestation of $\mathrm{Fe}_{3} \mathrm{C}$ carbide with alloying elements as substitution atoms was of relatively weak intensity. At the $0: C$ ratios in the charge of 1.42 and 1.17, there was an increase in the intensity of the $\mathrm{Fe}_{3} \mathrm{C}$ carbide manifestation. At the same time, the emergence of the carbide compounds $\mathrm{W}_{2} \mathrm{C} \cdot \mathrm{Mo}_{2} \mathrm{C}$ and $\mathrm{WC}$ was identified. Several phases with different content of alloying elements were present in the microstructure images. Cr content in the examined areas changed in the range of 0.64-33.86\% by weight; W content reached $41.58 \%$ by weight; Mo $-19.53 \%$ by weight; $V-18.55 \%$ by weight; Co $-3.95 \%$ by weight. The carbon content was in the range of $0.28-2.43 \%$ by weight. Analysis of the study results reveals that the most favorable ratio of $0: C$ in the charge was 1.42. At the same time, the phase composition was dominated by a solid solution of the alloying elements and carbon in $\alpha-F e$. The share of the residual carbon concentrated in the carbide component was in the range of $0.52-2.11 \%$ by weight, thereby ensuring the required reduction capability of the alloy when used. The study reported here has made it possible to identify new technological aspects of obtaining an alloy by utilizing anthropogenic waste, and whose indicators provide for the possibility of replacing part of standard ferroalloys when smelting steels without strict restrictions on carbon content

Keywords: oxide anthropogenic waste, alloy steel scale, reduction melting, $X$-ray phase studies
UDC $669.15^{\prime} 28-198$

DOI: $10.15587 / 1729-4061.2021 .238763$

\title{
IDENTIFICATION OF THE FEATURES OF STRUCTURAL-PHASE TRANSFORMATIONS IN THE PROCESSING OF WASTE FROM THE PRODUCTION OF HIGH-ALLOY STEELS
}

Viacheslav Borysov

Corresponding author Head of Laboratory*

E-mail: lab13borysow@gmail.com

Tetiana Solomko

Senior Researcher*

Mykhail Yamshinskij

Doctor of Technical Science, Associate Professor**

I van Lukianenko

$\mathrm{PhD}$ **

Bohdan Tsymbal

$\mathrm{PhD}$

Department of Occupational, Technogenic and Environmental Safety

National University of Civil Defence of Ukraine

Chernyshevska str., 94, Kharkiv, Ukraine, 61023

Andrey Andreev

Doctor of Pedagogical Sciences, Associate Professor, Head of Department Department of General and Applied Physics

Zaporizhzhia National University Zhukovskoho str., 66, Zaporizhzhia, Ukraine, 69600

Viacheslav Bratishko

Doctor of Technical Sciences, Senior Researcher, Dean Mechanical and Technological Faculty***

Tamara Bilko

$\mathrm{PhD}$, Associate Professor

Department of Occupational Safety and Environmental Engineering***

Vic tor Rebenko

$\mathrm{PhD}$, Associate Professor

Department of Mechanization of Animal Husbandry***

Te tiana Chorna

$\mathrm{PhD}$, Associate Professor

Department of Machine Usage in Agriculture

Dmytro Motornyi Tavria State Agrotechnological University

B. Khmelnytskoho ave., 18, Melitopol, Ukraine, 72312

*Research Laboratory of Applied Materials Science

Donbass Institute of Technique and Management Private Higher Educational Establishment «Academician Yuriy Bugay International Scientific and Technical University»

Mashynobudivnykiv blvd., 32, Kramatorsk, Ukraine, 84313

**Department of Foundry of Ferrous and Nonferrous Metals

National Technical University of Ukraine "Igor Sikorsky Kyiv Polytechnic Institute" Peremohy ave., 37, Kyiv, Ukraine, 03056 ***National University of Life and Environmental Sciences of Ukraine Heroiv Oborony str., 15, Kyiv, Ukraine, 03041

Received date 22.06.2021

Accepted date 11.08.2021 Published date 26.08.2021
How to Cite: Borysov, V., Solomko, T., Yamshinskij, M., Lukianenko, I., Tsymbal, B., Andreev, A., Bratishko, V., Bilko, T., Rebenko, V., Chorna, T. (2021). Identification of the features of structural-phase transformations in the processing of waste from the production of high-alloy steels. Eastern-European Journal of Enterprise Technologies, 4 (12 (112)), 33-38. doi:https://doi.org/10.15587/1729-4061.2021.238763

\section{Introduction}

Processing the anthropogenic waste and returning it to production is one of the ways to obtain alloying materials of refractory elements, prices for which tend to increase [1]. Finely dispersed and oxide industrial doped waste is not effectively utilized in any way. It is necessary to take into consideration the complex nature of the presence of elements 
in such waste when devising technological parameters for processing. These features predetermine difficulties in ensuring competitiveness, due to the issues related to the manufacturability and relatively high cost of production [2].

Thus, it is a relevant task to develop resource-saving technologies for processing alloyed anthropogenic waste with a decrease in the loss of alloying elements. To address such an issue, it is necessary to expand ideas on the physical-chemical transformations that occur during the reduction melting of anthropogenic raw materials.

\section{Literature review and problem statement}

The iron scale consists of $\mathrm{Fe}_{3} \mathrm{O}_{4}, \mathrm{Fe}_{2} \mathrm{O}_{3}$, and $\mathrm{FeO}$, which was reported in paper [3]; however, the authors of [4] have also detected $\mathrm{WO}_{2}$ and $\mathrm{W}_{2} \mathrm{C} \cdot \mathrm{Mo}_{2} \mathrm{C}$ in the high-speed steel scale. This is likely due to the increased level of doping. Work [3] investigated the carbon-based reduction of iron scale in the range of $750-1,050{ }^{\circ} \mathrm{C}$ that revealed $\mathrm{Fe}_{3} \mathrm{C}$ and $\mathrm{C}$, along with the iron phase, in the obtained products. The residual iron oxides manifested themselves only after heat treatment at $750{ }^{\circ} \mathrm{C}$. Close results related to the detection of $\mathrm{Fe}_{3} \mathrm{C}$ were reported in work [5] during the reduction melting of alloyed oxide waste containing Mo and Cr. In contrast, as noted in [6], the additional presence of $\mathrm{W}$ likely exerted an impact on the nature of carbide formations, which was reflected in the features of the microstructure. Individual particles, probably carbide, with an elevated level of carbon, containing tungsten and other elements, were found. The reduction of cobalt-containing precision alloy scale, described in work [7], was accompanied by the formation of iron-based phases without the manifestation of individual cobalt compounds. However, there were questions on determining the distribution of elements in the reduced material when studying the composition of the formed phases. Unresolved issues are related to identifying the most acceptable indicators for the reduction of anthropogenic raw materials in the Fe-W$\mathrm{Mo}-\mathrm{Cr}-\mathrm{V}-\mathrm{Co}-\mathrm{O}-\mathrm{C}$ system.

The authors of [8] demonstrated the possibility of the parallel formation of $\mathrm{Cr}_{23} \mathrm{C}_{6}, \mathrm{Cr}_{3} \mathrm{C}_{2}, \mathrm{Cr}_{7} \mathrm{C}_{3}$, and reduction in the $\mathrm{Fe}-\mathrm{Cr}-\mathrm{O}-\mathrm{C}$ system in the range of $1,273-1,773 \mathrm{~K}$. But the presence of other refractory elements could lead to the formation of more complex carbides of the $(\mathrm{Me}, \mathrm{Cr})_{\mathrm{m}} \mathrm{C}_{\mathrm{n}}$ type. A study into the carbon-based reduction of $\mathrm{FeO} \cdot \mathrm{V}_{2} \mathrm{O}_{3}$ and $\mathrm{FeO} \cdot \mathrm{Cr}_{2} \mathrm{O}_{3}$ oxides in the range of $1,100-1,250{ }^{\circ} \mathrm{C}$ was reported in [9]. When the $\mathrm{C}$ : $\mathrm{Fe}$ ratio in the charge changed from 0.8 to 1.4 , the degree of $\mathrm{Cr}$ and $\mathrm{V}(\%)$ extraction increased from 9.6 to 74.3 and from 10.0 to 45.3, respectively. At $1,250{ }^{\circ} \mathrm{C}$, the carbide formation increased. The disadvantage is the lack of data on the reduction of complex oxide compounds, which could be part of anthropogenic raw materials and cause differences in the course of reduction reactions. All that gives reason to assert the need to expand the ideas on the nature of the presence of elements in the reduced doped anthropogenic material involving the use of a combination of X-ray phase analysis, raster electron microscopy, and X-ray microanalysis.

The authors of [10], when reducing by carbon, confirmed the primary transformation of $\mathrm{MoO}_{3}$ into $\mathrm{MoO}_{2}$, which later was converted into Mo and carbides. However, unlike the case of molybdenum, when reducing $\mathrm{WO}_{3}$, the authors of [11] indicated the formation of several intermediate compounds of the $\mathrm{WO}_{\mathrm{x}}$ type. However, there was also a sequence of transformations in the reduction of higher oxides to lower ones, followed by the formation of a metal phase. Paper [12] describes similar stages in the transformations of tungsten oxide reduction at $750-900{ }^{\circ} \mathrm{C}$; but, at $1,450{ }^{\circ} \mathrm{C}$, there was an increase in carbide formation. The disadvantage is the impossibility to trace the sequence of transformations in the reduction processes in complex alloyed raw materials. Unresolved issues relate to determining the technological indicators for the reduction of complexly alloyed anthropogenic raw materials that could enable obtaining a material without the content of sublimation-prone components. At the same time, there would be no need to create additional conditions to decrease the loss of alloying elements with the gas phase.

Worth noting are the results of a study into the carbon-based reduction of anthropogenic waste of non-alloy steels, reported in work [3], which detected the phases of iron, iron carbide, carbon, and residual oxide component in the reduction products. Similar findings were presented by the authors of work [5] who investigated the reduction of alloyed anthropogenic waste involving carbon. In contrast, in work [6], the additional presence of $\mathrm{W}$ contributed to a clearer manifestation in the structure of formations that were likely of the carbide nature. At the same time, the phase composition of iron-containing anthropogenic alloyed oxide raw materials may contain compounds of alloying elements, as evidenced by the results from [4]. The reduction of cobalt-containing oxide anthropogenic waste was characterized by the absence of the formation of individual cobalt compounds in the presence of the phases and compounds of iron [7]. The studies of processes in the Fe-Cr-O-C systems [8] and Fe-V-O-C [9] established that, in parallel with the reduction, there were reactions that formed carbides. The stage character of transformations in the Mo-O-C [10] and $\mathrm{W}-\mathrm{O}-\mathrm{C}$ [11] systems was identified with the emergence of intermediate oxides, followed by the formation of metal and carbide phases [12]. Our review allows us to assert that it is advisable to conduct a study into determining the structural-phase features of the reduced anthropogenic raw materials, alloyed with $\mathrm{W}, \mathrm{Mo}, \mathrm{Cr}, \mathrm{V}, \mathrm{Co}$. At the same time, it is possible to achieve the required physical-chemical indicators in the reduction products by adjusting the $\mathrm{O}: \mathrm{C}$ ratio in the charge. Defining technological parameters for obtaining material without phases and compounds, with a significant predisposition to sublimation, could decrease the loss of alloying elements with the gas phase.

\section{The aim and objectives of the study}

The purpose of this research was to identify the features in the structural-phase transformations during the carbon-based reduction of oxide industrial waste from the production of high-speed steels, whereby when obtaining an alloy for doping. This is necessary to determine the most acceptable technological parameters to decrease the loss of refractory elements during the production and use of alloy as a doping additive when smelting steel.

To accomplish the aim, the following tasks have been set:

- to determine the features of the resulting phases in the alloy for doping when changing the ratio of $\mathrm{O}: \mathrm{C}$ in the charge, regarding the effect on decreasing the loss of alloying elements by sublimation when using the alloy;

- to examine the microstructure of the alloy for doping in combination with determining the content of elements on 
the surface areas of samples when changing the ratio of O:C in the charge by using raster electron microscopy and X-ray microanalysis.

\section{The study materials and methods}

4. 1. The examined materials and equipment used in the experiment

The starting raw material was the scale of the tungsten-molybdenum-cobalt-containing grades of high-speed steel, formed at the sites of metallurgical production. The reducer was carbon ultra-dispersed dust derived from carbon graphite production, the addition of which ensured the adjustment of the mass ratio of $\mathrm{O}: \mathrm{C}$ in the charge within 1.17-1.84. Adding the cuttings from the forced grinding of high-speed steel ensured the intensification of heat exchange in the initial stages of heating. Samples for our study were smelted in alundum crucibles in an indirect heating furnace with a coal lining. The smelting temperature was $1,873-1,913 \mathrm{~K}$. After smelting, the alundum crucibles were removed from the furnace together with the alloy and cooled at ambient temperatures.

The X-ray phase analysis of the samples was performed at the diffractometer "DRON-6" (Russia).

Images of the microstructure and the chemical composition of individual areas of the sample surface were acquired at the raster electron microscope "JSM-IT300" by JEOL (Japan), equipped with the $\mathrm{X}$-ray microanalysis system "X-MAX80" by Oxford Instruments (Great Britain).

4. 2. Procedure for conducting the experiments and determining the indicators of samples' properties

The phase composition of the samples was determined by X-ray analysis. Monochromatic radiation $\mathrm{Co} \mathrm{K} \alpha$ was used. The voltage on the tube and the anode current were $30 \mathrm{kV}$ and $20 \mathrm{~mA}$, respectively. PDWin 2.0 (Russia) software was used to determine the composition of phases.

The microstructure images were acquired at an accelerating voltage of $15 \mathrm{kV}$. The diameter of the electron probe was $4 \mathrm{~nm}$. The percentage of chemical elements was determined by a non-reference method for calculating fundamental parameters.

\section{The results of studying the properties of a doping alloy}

5.1. Determining features in the composition of the formed phases of a doped alloy

We determined the effect of the ratio of $\mathrm{O}: \mathrm{C}$ in the charge for smelt- ing a doped alloy based on the anthropogenic waste from high-speed steel on the phase composition of the alloy over the range of 1.17-1.84. At the ratio of $\mathrm{O}: \mathrm{C}$ in the charge of 1.84, a solid solution of carbon and alloying elements in the $\alpha$-Fe lattice was most clearly manifested in the phase composition at the relatively weak manifestation of $\mathrm{Fe}_{3} \mathrm{C}$ carbide (Fig. 1, $a$ ). Changing the ratio of $\mathrm{O}: \mathrm{C}$ in the charge from 1.84 to 1.42 leads to an increased intensity of the $\mathrm{Fe}_{3} \mathrm{C}$ diffraction maxima and a relatively weak fragmentary manifestation of the complex carbide compound of tungsten and molybdenum $\mathrm{W}_{2} \mathrm{C} \cdot \mathrm{Mo}_{2} \mathrm{C}$. Changing the $\mathrm{O}: \mathrm{C}$ ratio in the charge from 1.42 to 1.17 leads to a further increase in the $\mathrm{Fe}_{3} \mathrm{C}$ diffraction maxima and identification on the diffractogram of a more intense and clear manifestation of $\mathrm{W}_{2} \mathrm{C} \cdot \mathrm{Mo}_{2} \mathrm{C}$ carbide. At the same time, the presence of tungsten carbide WC was detected. The intensity of the manifestation of a solid solution of carbon and alloying elements in $\alpha$-Fe with a gradual change in the ratio of $\mathrm{O}: \mathrm{C}$ in the charge from 1.84 to 1.42 and 1.17 was characterized by a weakening in relation to carbide compounds.
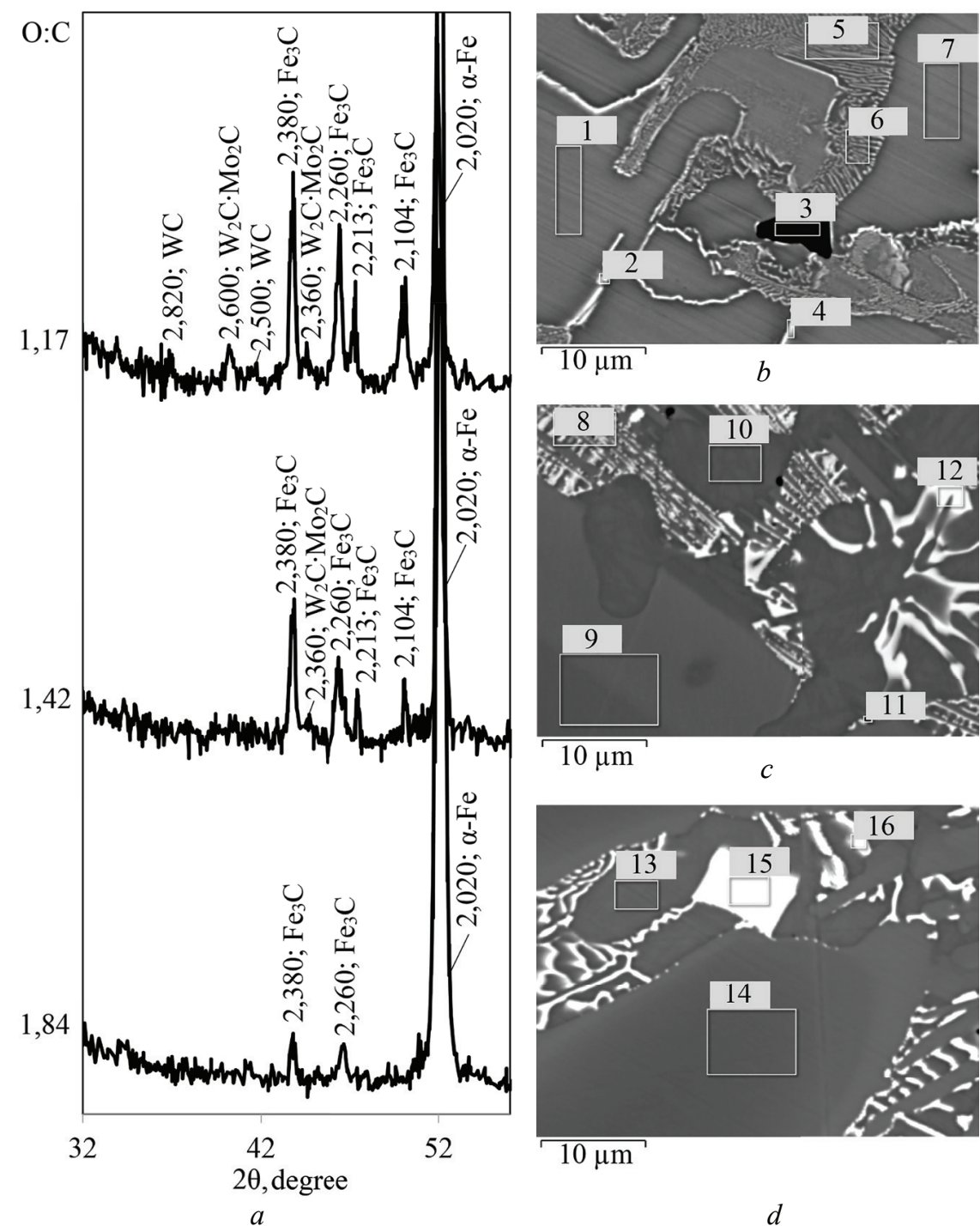

$b$
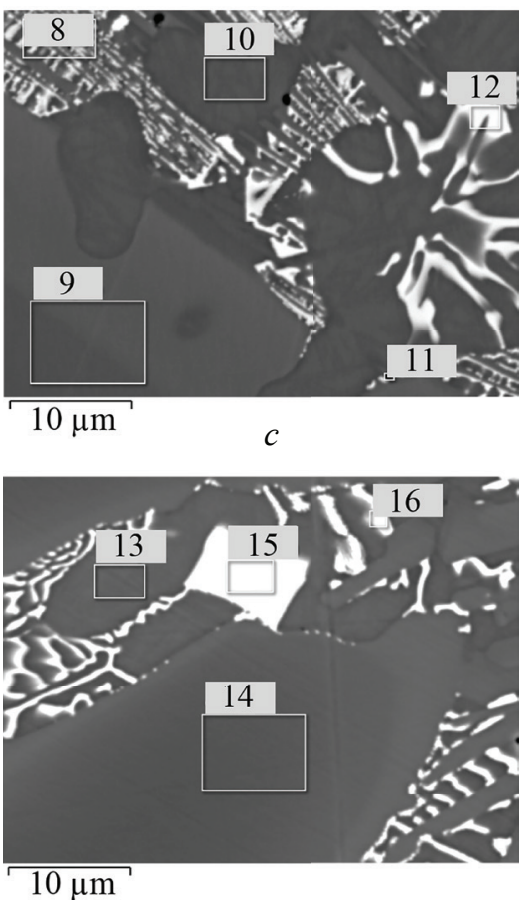

$d$

Fig. 1. X-ray phase study of the doped alloy at different ratios of $\mathrm{O}: \mathrm{C}$ in the charge and corresponding images of the microstructure at magnification $\times 3,000$ :

$a-$ areas of diffractograms; $b-1.84 ; c-1.42 ; d-1.17 ; 1-16-$ areas of the X-ray microanalysis of samples 
The detected phases do not have high pair elasticity and do not require the creation of special conditions to prevent the loss of alloying elements by sublimation when using the alloy during steel doping.

\section{2. Investigating the microstructure of a doped alloy}

It was found that the microstructure of the doped alloy is heterogeneous and is characterized by the presence of several variations of phase formations with different indicators of the content of elements (Fig. 1-3, Table 1).

The effect of the ratio of $\mathrm{O}: \mathrm{C}$ in the charge for the smelting of a doped alloy based on the anthropogenic waste from high-speed steels on the content of elements in the alloy was determined over the range of 1.17-1.84. A gradual change in the ratio of $\mathrm{O}: \mathrm{C}$ in the charge from 1.84 to 1.42 and 1.17 led to an increase in the alloy of residual carbon content (\% by weight) from $0.28-1.94$ to $0.52-2.11$ and $0.76-2.43$, respectively. At the same time, the content of Mo and W (\% by weight) changed from $0.00-8.92$ and $0.00-$ 14.87 to $0.99-15.76$ and $2.09-39.62$ and $1.37-19.53$ and $3.88-41.58$, respectively. The content of Co (\% by weight), respectively, changed from $0.00-2.46$ to $0.62-3.04$ and 0.07-3.95. The content of $\mathrm{Cr}$ and $\mathrm{V}$ in alloy areas within all the studied ratios of $\mathrm{O}: \mathrm{C}$ in the charge was in the range of $0.64-33.86 \%$ by weight and $0.00-18.55 \%$ by weight. Residual oxygen in the amount of $22.49 \%$ by weight was detected only in a separate inclusion with a ratio of $\mathrm{O}: \mathrm{C}$ in the charge of 1.84 , which may be due to the insufficient amount of the reducer in the charge. The achieved level of residual carbon content in the alloy at the ratios $\mathrm{O}: \mathrm{C}$ in the charge of 1.42 and 1.17 in the form of carbide compounds during alloying leads to the dissolution of refractory alloying elements in steel ensuring a relatively high reducing capability. In terms of the possibility to provide relatively higher cost coefficients for the use of an alloy, the most acceptable ratio of O:C in the charge is 1.42 . This is due to the relatively lower residual carbon content (as opposed to the case of the ratio of $\mathrm{O}: \mathrm{C}$ in the charge of 1.17), which is sufficient to ensure the required reduction capability of the alloy at doping.
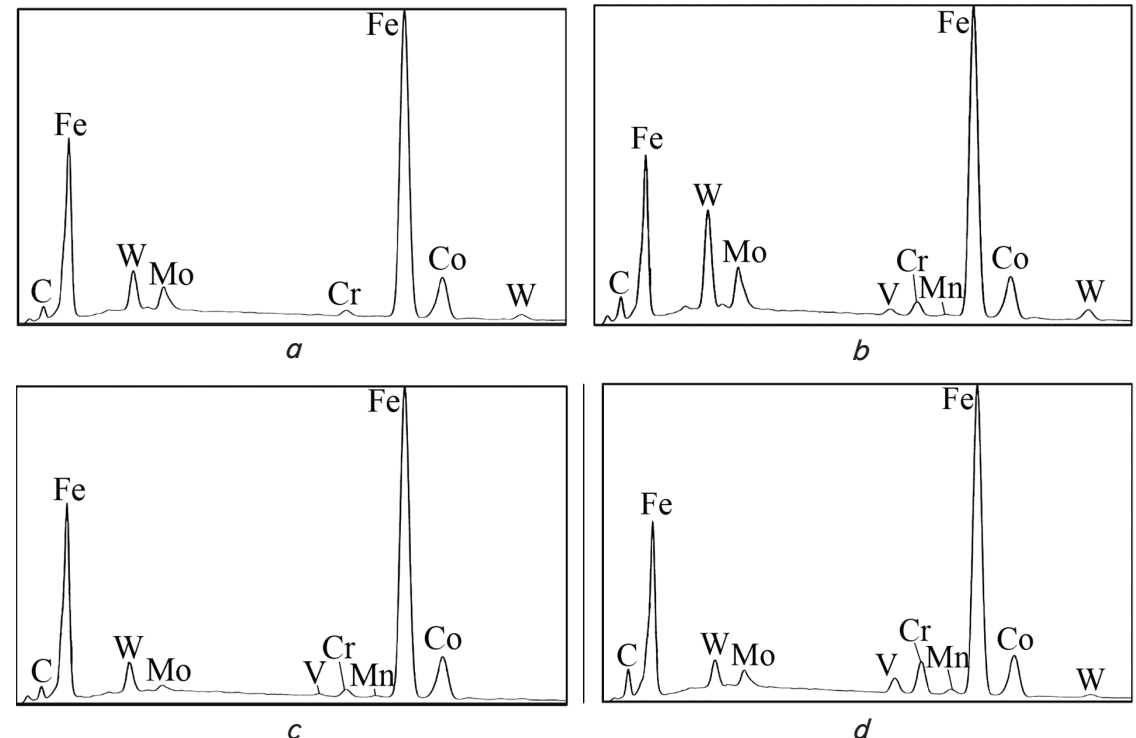

Fig. 2. Spectrograms of some of the areas from the X-ray microanalysis of the doped alloy, corresponding to Fig. $1: a-1 ; b-8 ; c-10 ; d-14$

Studying the distribution of elements (Fig. 3) indicates a match between the concentration zones of $\mathrm{Cr}, \mathrm{V}, \mathrm{Mo}, \mathrm{W}$ and carbon, as well as Fe and Co. The presence of manganese and titanium demonstrated a relatively low and fragmentary manifestation at the level of concomitant impurities.

Table 1

Results of the X-ray microanalysis of the doped alloy, corresponding to Fig. 1

\begin{tabular}{|c|c|c|c|c|c|c|c|c|c|c|c|}
\hline \multirow{2}{*}{ No. of entry } & \multicolumn{10}{|c|}{ Elemental composition, \% by weight } \\
\cline { 2 - 14 } & $\mathrm{C}$ & $\mathrm{O}$ & $\mathrm{Ti}$ & $\mathrm{V}$ & $\mathrm{Cr}$ & $\mathrm{Mn}$ & $\mathrm{Fe}$ & $\mathrm{Co}$ & $\mathrm{Mo}$ & $\mathrm{W}$ & Total \\
\hline 1 & 0.41 & 0.00 & 0.00 & 0.00 & 0.81 & 0.00 & 84.56 & 2.46 & 3.96 & 7.80 & 100.00 \\
\hline 2 & 1.94 & 0.00 & 0.00 & 0.00 & 1.05 & 0.00 & 71.16 & 2.06 & 8.92 & 14.87 & 100.00 \\
\hline 3 & 0.28 & 22.49 & 0.00 & 15.51 & 33.86 & 1.50 & 26.36 & 0.00 & 0.00 & 0.00 & 100.00 \\
\hline 4 & 1.72 & 0.00 & 0.00 & 0.00 & 1.17 & 0.00 & 72.50 & 2.13 & 8.32 & 14.16 & 100.00 \\
\hline 5 & 1.23 & 0.00 & 0.00 & 0.00 & 0.81 & 0.00 & 83.92 & 2.33 & 4.15 & 7.56 & 100.00 \\
\hline 6 & 1.37 & 0.00 & 0.00 & 0.00 & 0.94 & 0.00 & 82.22 & 2.15 & 4.50 & 8.82 & 100.00 \\
\hline 7 & 0.36 & 0.00 & 0.00 & 0.00 & 0.91 & 0.00 & 84.84 & 2.45 & 3.69 & 7.75 & 100.00 \\
\hline 8 & 0.93 & 0.00 & 0.00 & 0.64 & 1.73 & 0.08 & 76.07 & 2.24 & 6.15 & 12.16 & 100.00 \\
\hline 9 & 1.05 & 0.00 & 0.00 & 2.00 & 4.88 & 0.22 & 82.73 & 1.69 & 2.59 & 4.84 & 100.00 \\
\hline 10 & 0.52 & 0.00 & 0.00 & 0.28 & 1.06 & 0.21 & 91.81 & 3.04 & 0.99 & 2.09 & 100.00 \\
\hline 11 & 0.88 & 0.00 & 0.00 & 0.79 & 1.76 & 0.08 & 77.22 & 2.18 & 5.92 & 11.17 & 100.00 \\
\hline 12 & 2.11 & 0.00 & 0.15 & 14.21 & 1.89 & 0.12 & 25.52 & 0.62 & 15.76 & 39.62 & 100.00 \\
\hline 13 & 0.76 & 0.00 & 0.00 & 0.21 & 0.64 & 0.15 & 88.85 & 3.95 & 1.37 & 4.07 & 100.00 \\
\hline 14 & 1.34 & 0.00 & 0.00 & 1.96 & 4.31 & 0.25 & 83.91 & 1.83 & 2.52 & 3.88 & 100.00 \\
\hline 15 & 2.43 & 0.00 & 1.52 & 18.55 & 1.49 & 0.14 & 17.76 & 0.07 & 16.46 & 41.58 & 100.00 \\
\hline 16 & 2.27 & 0.00 & 0.00 & 0.76 & 0.76 & 0.10 & 38.77 & 1.36 & 19.53 & 36.45 & 100.00 \\
\hline
\end{tabular}




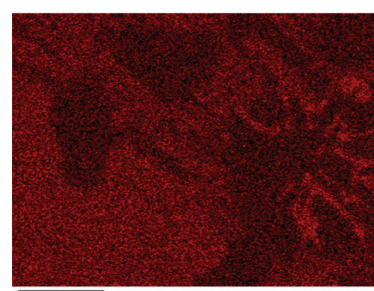

$\widehat{10 \mu \mathrm{m}}$

$a$

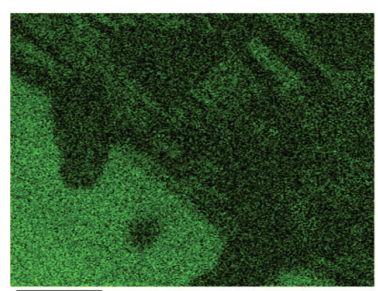

$\longdiv { 1 0 \mu \mathrm { m } }$

c

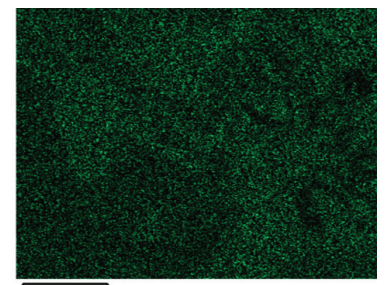

$\overparen{10 \mu \mathrm{m}}$

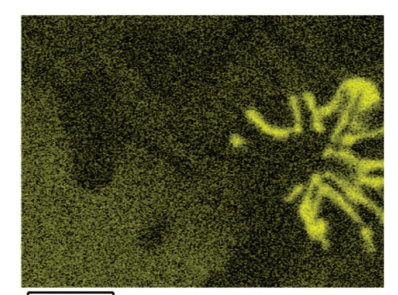

$\widehat{10 \mu \mathrm{m}}$

b

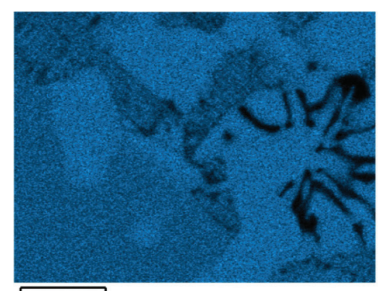

$\overparen{10 \mu \mathrm{m}}$

$d$

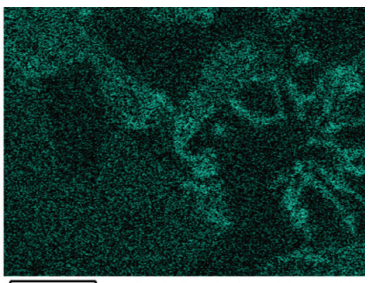

$\overparen{10 \mu \mathrm{m}}$

e

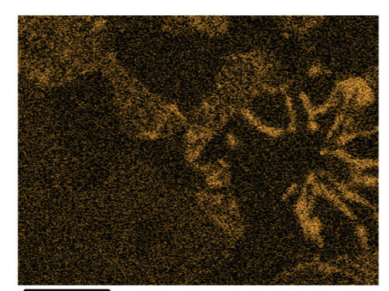

$\overparen{10 \mu \mathrm{m}}$

Fig. 3. Distribution of basic elements in characteristic X-rays according to Fig. 1, $c$ (magnification $\times 3,000$ ). The greater content of the element corresponds to a more intense color: $a-\mathrm{C} ; b-\mathrm{V} ; c-\mathrm{Cr} ; d-\mathrm{Fe}$; $e-\mathrm{Co}$;

$$
f-\mathrm{Mo} ; g-\mathrm{W}
$$

\section{Discussion of results of studying the properties of a} doped alloy

Alloying elements in the alloy were to a greater extent in the form of replacement atoms in iron-based phases with increased carbide formation at a ratio of $\mathrm{O}: \mathrm{C}$ in the charge of 1.42 and 1.17 (Fig. 1). This is consistent with the results reported in [5]. However, the difference is the formation of $\mathrm{W}_{2} \mathrm{C} \cdot \mathrm{Mo}_{2} \mathrm{C}$ and $\mathrm{WC}$ - separate compounds of refractory elements, which was also noted in [4]. In [6], no compounds of alloying elements were clearly detected while studying the structure of reduction products indicated the possibility of the presence of carbides of refractory elements. Based on the distribution of elements (Fig. 1-3, Table 1), Co was, in dominant amount, in the solid solution in an iron lattice. For example, sections 10 and 13 (Fig. 1) were characterized by relatively high concentrations (\% by weight) of both $\mathrm{Fe}$ in the amount of 91.81 and 88.85, respectively, and Co -3.04 and

3.95 , respectively. This is consistent with the results reported in [7], in which, as a disadvantage, one should note the lack of research involving X-ray microanalysis to detect the composition of individual phase formations. Areas of an alloy with high carbon content and alloying elements can be carbide phases (Fig. 1-3, Table 1). This is consistent with the results reported in [8], whose authors indicate the formation of $\mathrm{Cr}$ carbides in parallel with the reduction processes. At the same time, there is a tendency to increase the maximum content of carbide-forming elements such as Mo and W in the studied alloy areas when changing the $\mathrm{O}: \mathrm{C}$ ratio in the charge from 1.84 to 1.42 and 1.17. Thus, the content of Mo and W (\% by weight) at the ratio of $\mathrm{O}: \mathrm{C}$ in the charge of 1.84 was 8.92 and 14.87 , respectively, at $1.42-15.76$ and 39.62 , respectively, at $1.17-$ 19.53 and 41.58, respectively. That further indicates the evolution of molybdenum- and tungsten-containing carbide phases and is consistent with the results of the phase studies that detected the presence of $\mathrm{W}_{2} \mathrm{C} \cdot \mathrm{Mo}_{2} \mathrm{C}$ (Fig. 1,a). Correspondence is also observed with the results of works, which indicate the development of carbide formation during the reduction of oxide compounds Mo [10] and W [12]. However, as a difference, the examined inclusions contain several alloying elements at once, which predetermines a more complex nature of interaction and the formation of complex carbide compounds. The difference in the nature of alloying of the formed particles with a relatively high carbon content indicates the presence of several variations of carbide phases with refractory elements (Fig. 1-3, Table 1). Detection of oxygen in a separate fragmentary portion in the amount of $22.49 \%$ by weight (Fig. 1, b, area 3) at the ratio of O:C in the charge of 1.84 indicates the oxide nature of the formation. The data, given in paper [3], also indicated a possibility of the presence of the residual oxide component at a relatively low temperature of heat treatment. However, in contrast, with the ratio of O:C in the charge of 1.84, the likely cause is the insufficient amount of carbon, which led to incomplete reduction of certain areas. At the ratio of $\mathrm{O}: \mathrm{C}$ in the charge of 1.17, there was an intensive manifestation of carbides due to the relatively high residual carbon, which limits the cost coefficients of alloy use. However, as shown by the results reported [9], to increase the degree of extraction of alloying elements, some excess carbon reducer in the charge is required. From this position, based on our studies, the most acceptable ratio of $\mathrm{O}: \mathrm{C}$ in the charge is 1.42 . In this case, there was a relatively low level of residual carbon in the form of carbides, but sufficient to ensure the necessary reduction capability of the alloy at doping.

Certain limitations in the use of the alloy may be associated with complex alloying. Problems may arise if one or more components of the alloy are strictly limited in the target product, which may cause exceeding the established limits of elements in the composition. To avoid this kind of problems and provide relatively high cost coefficients, it is necessary to ensure that the composition of the elements in the alloy and the target product is approximate.

As a disadvantage, we can indicate the absence of images of the microstructure with different magnifications. Such a presentation of the research results would provide a greater demonstration.

This area could be advanced by engaging other grades of steel and alloys in the processing of anthropogenic industrial waste. The difficulties in trying to develop the current study relate to the lack of sufficient experimental base.

The indicators of the resulting alloy make it possible to smelt such grades of alloyed steel that do not have strict 
carbon restrictions when replacing part of the standard ferroalloys. From this point of view, the high-speed steel of grades R6M5K5, R9M4K8 (GOST 19265-73) and others are promising, whose smelting is carried out in an electric furnace. In the resulting alloy, there are no compounds and phases with a relatively high predisposition to sublimation. That is, there is no need to create special conditions that prevent the evaporation and loss of alloying elements with the gas phase, which predetermines an increase in the utilization of alloying elements.

\section{Conclusions}

1. It has been established that at the ratio of $\mathrm{O}: \mathrm{C}$ in the charge of 1.84, a solid solution of carbon and alloying elements in the $\alpha$-Fe and $\mathrm{Fe}_{3} \mathrm{C}$ was detected in the phase composition. A change in the $\mathrm{O}: \mathrm{C}$ ratio in the charge from 1.84 to 1.42 led to an increase in the $\mathrm{Fe}_{3} \mathrm{C}$ manifestation and the detection of the presence of complex carbide $\mathrm{W}_{2} \mathrm{C} \cdot \mathrm{Mo}_{2} \mathrm{C}$ in the alloy. When the $\mathrm{O}: \mathrm{C}$ ratio in the charge changed from 1.42 to 1.17 , there was a further increase in the intensity of $\mathrm{Fe}_{3} \mathrm{C}$ diffraction maxima, along with the detection of WC carbide and the increased clarity of the $\mathrm{W}_{2} \mathrm{C} \cdot \mathrm{Mo}_{2} \mathrm{C}$ manifestation. When changing the ratio of $\mathrm{O}: \mathrm{C}$ in the charge from 1.84 to 1.42 and 1.17 in the alloy, there was a weakening of the manifestation of the solid solution of carbon and alloying elements in $\alpha$-Fe relative to carbides. The detected phases do not tend to sublimation, which eliminates the need to create special conditions for preventing the loss of alloying elements with the gas phase when using the alloy during steel doping.

2. It has been determined that the microstructure of the doped alloy at the different ratios of $\mathrm{O}: \mathrm{C}$ in the charge was characterized by the presence of phase formations that differed in shape, size, and chemical composition. Changing the ratio of $\mathrm{O}: \mathrm{C}$ in the charge from 1.84 to 1.42 and 1.17 led to an increase in the alloy of residual carbon content (\% by weight) from $0.28-1.94$ to $0.52-2.11$ and $0.76-2.43$, respectively. At the same time, the content of Mo and W (\% by weight) changed from $0.00-8.92$ and $0.00-14.87$ to $0.99-15.76$ and 2.09-39.62 and 1.37-19.53 and 3.88-41.58, respectively. The content of Co (\% by weight), respectively, changed from $0.00-2.46$ to $0.62-3.04$ and $0.07-3.95$. The content of $\mathrm{Cr}$ and $\mathrm{V}$ in the alloy areas within all the studied ratios of $\mathrm{O}: \mathrm{C}$ in the charge was in the range of $0.64-33.86 \%$ by weight and $0.00-18.55 \%$ by weight, respectively. Oxygen was detected fragmentary in a separate inclusion at the level of $22.49 \%$ by weight, which may be a non-reduced component. Particles with elevated levels of carbon and alloying elements of various shapes and compositions, presumably of carbide nature, were found.

References

1. Henckens, M. L. C. M., van Ierland, E. C., Driessen, P. P. J., Worrell, E. (2016). Mineral resources: Geological scarcity, market price trends, and future generations. Resources Policy, 49, 102-111. doi: https://doi.org/10.1016/j.resourpol.2016.04.012

2. Sekiguchi, N. (2017). Trade specialisation patterns in major steelmaking economies: the role of advanced economies and the implications for rapid growth in emerging market and developing economies in the global steel market. Mineral Economics, 30 (3), 207-227. doi: https://doi.org/10.1007/s13563-017-0110-2

3. Mechachti, S, Benchiheub, O., Serrai, S., Shalabi, M. (2013). Preparation of iron Powders by Reduction of Rolling Mill Scale. International Journal of Scientific \& Engineering Research, 4 (5), 1467-1472.

4. Grigor'ev, S. M., Petrishchev, A. S. (2012). Assessing the phase and structural features of the scale on P6M5Ф3 and P12M3K5Ф2 steel. Steel in Translation, 42 (3), 272-275. doi: https://doi.org/10.3103/s0967091212030059

5. Petryshchev, A., Milko, D., Borysov, V., Tsymbal, B., Hevko, I., Borysova, S., Semenchuk, A. (2019). Studying the physicalchemical transformations at resourcesaving reduction melting of chrome-nickelcontaining metallurgical waste. Eastern-European Journal of Enterprise Technologies, 2 (12 (98)), 59-64. doi: https://doi.org/10.15587/1729-4061.2019.160755

6. Borysov, V., Lytvynov, A., Braginets, N., Petryshchev, A., Artemev, S., Tsymbal, B. et. al. (2020). Features of the phase and structural transformations in the processing of industrial waste from the production of highalloyed steels. Eastern-European Journal of Enterprise Technologies, 3 (10 (105)), 48-54. doi: https://doi.org/10.15587/1729-4061.2020.205779

7. Hryhoriev, S., Petryshchev, A., Shyshkanova, G., Zaytseva, T., Frydman, O., Sergienko, O. et. al. (2017). Research into recycling of nickelcobaltcontaining metallurgical wastes by the ecologicallysafe technique of hydrogen reduction. Eastern-European Journal of Enterprise Technologies, 6 (10 (90)), 45-50. doi: https://doi.org/10.15587/1729-4061.2017.114348

8. Simonov, V. K., Grishin, A. M. (2013). Thermodynamic analysis and the mechanism of the solid-phase reduction of $\mathrm{Cr}_{2} \mathrm{O}_{3}$ with carbon: Part 1. Russian Metallurgy (Metally), 2013 (6), 425-429. doi: https://doi.org/10.1134/s0036029513060153

9. Zhao, L., Wang, L., Chen, D., Zhao, H., Liu, Y., Qi, T. (2015). Behaviors of vanadium and chromium in coal-based direct reduction of high-chromium vanadium-bearing titanomagnetite concentrates followed by magnetic separation. Transactions of Nonferrous Metals Society of China, 25 (4), 1325-1333. doi: https://doi.org/10.1016/s1003-6326(15)63731-1

10. Zhu, H., Li, Z., Yang, H., Luo, L. (2013). Carbothermic Reduction of MoO3 for Direct Alloying Process. Journal of Iron and Steel Research International, 20 (10), 51-56. doi: https://doi.org/10.1016/s1006-706x(13)60176-4

11. Baghdasaryan, A. M., Niazyan, O. M., Khachatryan, H. L., Kharatyan, S. L. (2014). DTA/TG study of tungsten oxide and ammonium tungstate reduction by $(\mathrm{Mg}+\mathrm{C})$ combined reducers at non-isothermal conditions. International Journal of Refractory Metals and Hard Materials, 43, 216-221. doi: https://doi.org/10.1016/j.ijrmhm.2013.12.003

12. Islam, M., Martinez-Duarte, R. (2017). A sustainable approach for tungsten carbide synthesis using renewable biopolymers. Ceramics International, 43 (13), 10546-10553. doi: https://doi.org/10.1016/j.ceramint.2017.05.118 